\title{
ANATOMIA DA MADEIRA DE MYRCIANTHES GIGANTEA (Legr.) Legr. ${ }^{1}$
}

\author{
JOSÉ NEWTON CARDOSO MARCHIORI ${ }^{2}$ LUCIANODENARDI $^{3}$ MARCOS ROBERTO FERREIRA $^{4}$
}

\section{RESUMO}

A estrutura anatômica do xilema secundário de Myrcianthes gigantea (Legr.) Legr. é descrita e ilustrada com fotomicrografias. O lenho apresenta poros solitários, parênquima apotraqueal difuso-em-agregados, raios heterogêneos e fibras com pontoações areoladas. A ausência de traqueídeos vasicêntricos e de cristais no parênquima axial permitem separar a espécie de outras Mirtoídeas nativas no Rio Grande do Sul.

Palavras-chave: Anatomia da madeira, Myrtaceae, Myrcianthes gigantea.

\section{ABSTRACT}

[Wood anatomy of Myrcianthes gigantea (Legr.) Legr.].

The wood of Myrcianthes gigantea (Legr.) Legr. is anatomically described and illustrated with photomicrographs. The anatomical structure shows solitary vessels, diffuse-in-aggregates apotracheal parenchyma, heterogeneous rays and fibres with bordered pits. The absence of vasicentric tracheids as well as chrystals in the axial parenchyma distinguishes the species from other native Myrtoids from the State of Rio Grande do Sul.

Key-words: Wood anatomy, Myrtaceae, Myrcianthes gigantea.

\section{INTRODUÇÃO}

A família Myrtaceae reúne numerosas espécies da subfamília Myrtoideae no continente americano e apenas Tepualia stipularis, que habita no extremo sul do Chile e Argentina, entre as Leptospermoideae.

Dos 24 gêneros representados na flora brasileira, 19 ocorrem no Rio Grande do Sul: Acca, Blepharocalyx, Calycorectes, Calyptranthes, Campomanesia, Eugenia, Gomidesia, Hexachlamys, Marlierea, Myrceugenia, Myrcia, Myrcianthes, Myrciaria, Myrrhinium, Neomitranthes, Paramyrciaria, Plinia, Psidium e Sphoneugena (Marchiori \& Sobral, 1997).

Com cerca de 50 espécies (Rotman, 1979), o gênero Myrcianthes Berg. apresenta três espécies no Rio Grande do Sul: Myrcianthes cisplatensis (Camb.) Berg, Myrcianthes pungens (Berg) Legr. e Myrcianthes gigantea (Legr.) Legr. (Marchiori \& Sobral, 1997).

Conhecida regionalmente por araçá-do-mato, Myrcianthes gigantea alcança $15 \mathrm{~m}$ de altura e distribui-se do norte do Uruguai (o tipo procede de Quebrada de Los Cuervos, Taquarembó) até o nordeste brasileiro, habitando, no Rio Grande do Sul, principalmente a submata dos pinhais e capões, na Serra do Sudeste, Planalto Médio e Depressão Central (Marchiori \& Sobral, 1997).

Sobre a anatomia das Mirtáceas, Metcalfe \& Chalk (1972) referem: vasos usualmente pequenos, numerosos e solitários; elementos vasculares médios até grandes, com placas de perfuração simples e pontoações intervasculares

1 Recebido em 05/05/2007 e aceito para publicação em 17/08/2007.

2 Engenheiro Florestal, Dr., bolsista de Produtividade em Pesquisa do CNPq, professor Titular do Departamento de Ciências Florestais, Universidade Federal de Santa Maria, CEP 97105-900, Santa Maria (RS). balduinia@mail.ufsm.br

3 Engenheiro Florestal, Bolsista do CNPq - Brasil, Doutorando do Programa de Pós-Graduação em Engenharia Florestal, Universidade Federal de Santa Maria, CEP 97105-900, Santa Maria (RS). lucianodenardi@yahoo.com.br

4 Acadêmico do Curso de Graduação em Engenharia Florestal, Universidade Federal de Santa Maria, CEP 97105-900, Santa Maria(RS).markus@mail.ufsm.br 
alternas, pequenas, ornamentadas; e raios usualmente heterogêneos, exclusivamente unisseriados, ou então multisseriados, com 2-3 (até 6) células de largura. O parênquima, tipicamente apotraqueal-difuso ou em faixas unisseriadas, nas madeiras com poros solitários, é predominantemente paratraqueal nas com múltiplos numerosos, ao passo que as fibras, com pontoações tipicamente areoladas, são geralmente de comprimento médio. Traqueídeos vasicêntricos são freqüentes na família, mas canais intercelulares axiais, de origem traumática, restringem-se a poucos gêneros. Marchiori \& Sobral (1997) comentam que o conjunto desses caracteres sugere primitividade ao xilema das Mirtáceas.

O presente trabalho visa a descrição e análise da estrutura anatômica da madeira de Myrcianthes gigantea, tendo por base referências bibliográficas sobre outras Mirtoídeas nativas do Rio Grande do Sul.

\section{MATERIAL E MÉTODO}

O material em estudo consiste de uma amostra de madeira e respectivo material botânico, coletados Santana da Boa Vista - RS (Cerro do Diogo), e anexados à Xiloteca e Herbário do Departamento de Ciências Florestais da Universidade Federal de Santa Maria (HDCF), sob o número 2151.

$\mathrm{Da}$ amostra de madeira, foram preparados três corpos-de-prova com $2 \mathrm{~cm}$ de lado, extraídos da porção mais externa do lenho e orientados para obtenção de cortes histológicos nos planos transversal, longitudinal radial e longitudinal tangencial. Um quarto bloco foi também retirado, com vistas à maceração.

No preparo das lâminas histológicas, seguiuse a técnica padrão no Laboratório de Anatomia da Madeira da Universidade Federal do Paraná: os corpos-de-prova foram amolecidos por fervura em água e seccionados em micrótomo de deslize, regulado na espessura de $18 \mu \mathrm{m}$. Os cortes foram tingidos com acridinavermelha, crisoidina e azul-de-astra (Dujardin, 1964), desidratados em série alcoólica, diafanizados em xilol e montados em lâminas permanentes, com "Entellan".

Para a confecção de lâminas de macerado, o lenho foi dissociado pelo método de Jeffrey (Burger \& Richter, 1991); no preparo de lâminas usou-se coloração com safranina $1 \%$ e "Entellan" como meio de montagem.

A descrição microscópica baseia-se nas recomendações do IAWA Committee (1989) e a determinação dos diferentes tipos celulares, na metodologia proposta por Marchiori (1980); foram mensuradas, ainda, a altura de raios em micrômetros e em número de células. Os dados quantitativos da madeira são exibidos na Tabela 1.

As fotomicrografias foram tomadas em aparelho Carl Zeiss, no Laboratório de Anatomia da Madeira da Universidade Federal do Paraná.

\section{DESCRIÇÃO MICROSCÓPICA}

Camadas de crescimento: distintas, marcadas por fibras radialmente estreitas no lenho tardio (Figura 1A).

Vasos: com freqüência de $161 \pm 25(131-$ $200)^{*}$ por $\mathrm{mm}^{2}$ (Figura 1A) e $27 \pm 4(17-32)$ $\mu \mathrm{m}$ de diâmetro; exclusivamente solitários e em distribuição difusa (Figura 1A, B). Elementos vasculares de $542 \pm 68(400-650) \mu \mathrm{m}$ de comprimento, com placas de perfuração simples, oblíquas (Figura 1D) e apêndices geralmente em ambas as extremidades. Pontoações raiovasculares distintamente areoladas; pontoações intervasculares, não observadas devido ao escasso contato entre vasos. Espessamentos espiralados, traqueídeos vasicêntricos, tiloses e gomas, ausentes no material em estudo.

Parênquima axial: apotraqueal difuso-emagregados, tendendo a formar faixas estreitas ou linhas (Figura 1A, B); composto, geralmente, de 5 a 8 células por série. Cristais, ausentes.

Raios: com $1-3$ células de largura (Figura 1D) e $198 \pm 66(100$ - 312) $\mu \mathrm{m}$ de altura; não estratificados e com freqüência superior a 14/mm.

\footnotetext{
* $\mathrm{x} \pm \mathrm{s}$ (valor mínimo - valor máximo), onde: $\mathrm{x}=$ média; $\mathrm{s}=$ desvio padrão.
} 

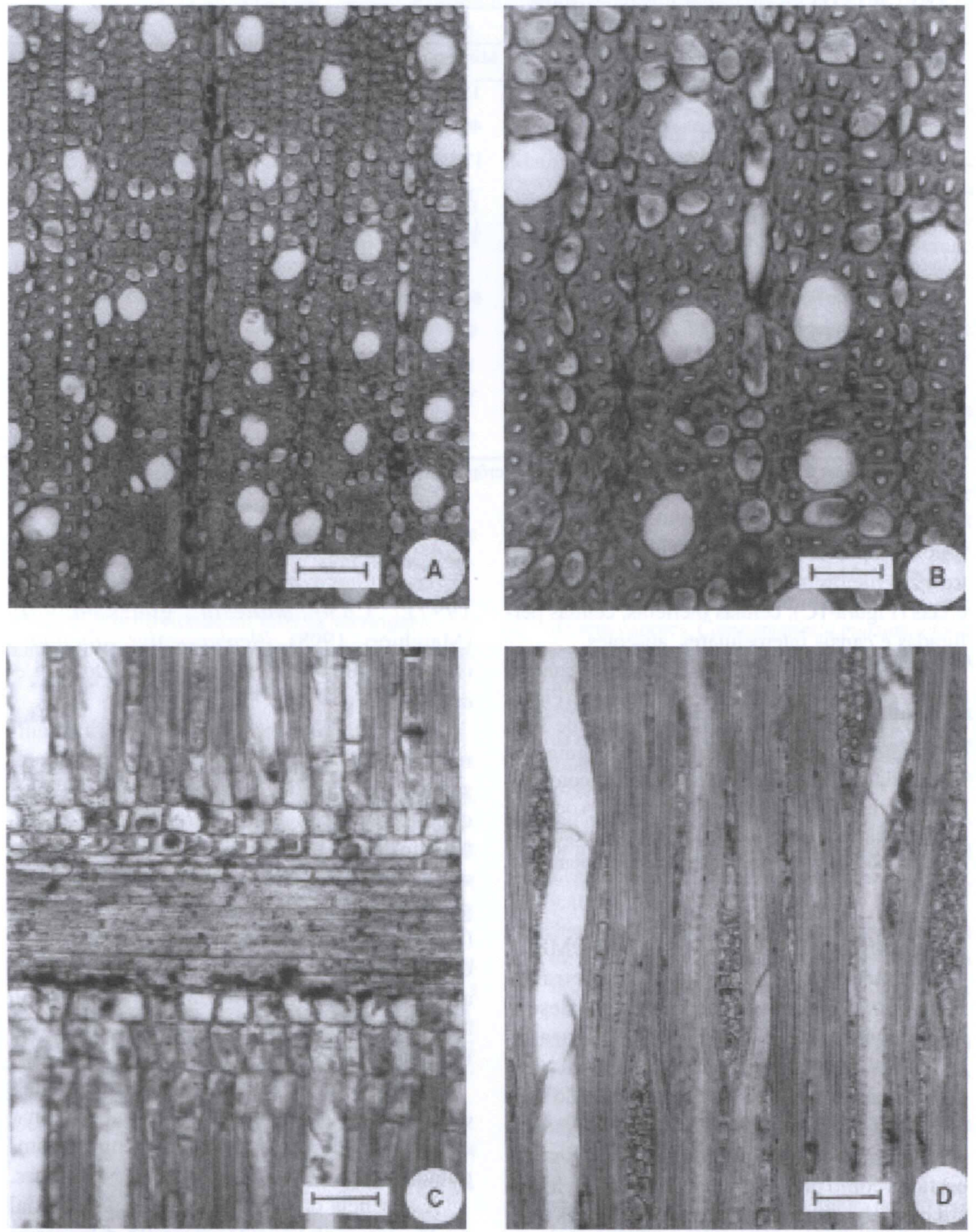

FIGURA 1: Fotomicrografias da madeira de Myrcianthes gigantea. A, B - Anel de crescimento distinto, poros solitários e parênquima apotraqueal difuso-em-agregados, em plano transversal (escala $\mathrm{A}=50 \mu \mathrm{m} ; \mathrm{B}=100 \mu \mathrm{m}$ ). $\mathrm{C}$ - Raio heterogêneo, em seção radial, com células procumbentes, quadradas e eretas (escala $=50 \mu \mathrm{m}$ ). D - Raios com 1-3 células de largura e vasos com placas de perfuração oblíquas, em seção tangencial (escala $=50 \mu \mathrm{m})$. 
TABELA 1: Dados quantitativos da estrutura anatômica.

\begin{tabular}{lccccc}
\hline Característica & Mínimo & Média & Máximo & $\mathrm{s}$ & CV (\%) \\
\hline Freqüência de vasos (vasos $\left./ \mathrm{mm}^{2}\right)$ & 131 & 161,2 & 200 & 25,5410 & 15,8 \\
Comprimento de elementos vasculares $(\mu \mathrm{m})$ & 400 & 542 & 650 & 68,2519 & 12,6 \\
Diâmetro do lume de vasos $(\mu \mathrm{m})$ & 17,5 & 27,5 & 32,5 & 3,9528 & 14,4 \\
Freqüência de raios $(\mathrm{mm})$ & 10 & 14 & 17 & 1,7483 & 12,3 \\
Altura de raios $(\mu \mathrm{m})$ & 100 & 197,9 & 312,5 & 66,3116 & 33,5 \\
Altura de raios (células) & 3 & 8,7 & 16 & 3,7336 & 42,6 \\
Comprimento de fibras $(\mu \mathrm{m})$ & 660 & 875,2 & 1140 & 125,6025 & 11 \\
Fração de vasos (\%) & 13 & 16 & 18 & 1,8708 & 11,7 \\
Fração de parênquima axial $(\%)$ & 10 & 14,2 & 16 & 2,4899 & 17,5 \\
Fração de raios(\%) & 16 & 19 & 21 & 1,8708 & 9,8 \\
Fração de fibras(\%) & 47 & 50,8 & 53 & 2,3875 & 4,7 \\
\hline
\end{tabular}

$\mathrm{s}=$ desvio padrão; $\mathrm{CV}=$ coefíciente de variação; $\mu \mathrm{m}=$ micrômetros.

Raios compostos de células procumbentes no centro e 2-4 fileiras marginais de células quadradas e eretas (Figura 1C); células oleíferas, células perfuradas e canais intercelulares, ausentes.

Fibras: de $875 \pm 125(660-1140) \mu \mathrm{m}$ de comprimento, com paredes estreitas até espessas (Figura 1A, B) e pontoações areoladas com menos de $3 \mu \mathrm{m}$ de diâmetro; fibras septadas, espessamentos espiralados e cristais, ausentes. Quanto à composição do lenho, as fibras correspondem a $51 \%$ do total, seguida pelos raios (19\%), vasos (16\%) e parênquima axial (14\%). Máculas medulares, ocasionalmente presentes.

\section{ANÁLISE DA ESTRUTURA ANATÔMICA}

A estrutura anatômica da madeira de Myrcianthes gigantea concorda com o descrito por Metcalfe e Chalk (1972) para as Mirtáceas. A presença de poros solitários e em distribuição difusa, de placas de perfuração simples, de fibras com pontoações areoladas, de parênquima apotraqueal e de raios heterogêneos, tidos como predominantes na família, foram também observados em outras Mirtoídeas nativas do Rio Grande do Sul: Feijoa sellowiana (Marchiori, 1984a), Myrrhinium loranthoides (Marchiori, 1984c), Myrceugenia myrtoides (Marchiori \& Muñiz, 1987b), Myrceugenia glaucescens (Marchiori \& Muñiz, 1988), Calyptranthes concinna (Marchiori \& Brum, 1997), Campomanesia guazumaefolia (Marchiori, 1998), Blepharocalyx salicifolius (Denardi, 2004) e Plinia rivularis (Denardi et al., 2005).

À semelhança das espécies anteriormente referidas, Myrcianthes gigantea também apresenta fibrotraqueídeos. Cabe lembrar, todavia, que fibras com pontoações areoladas de diâmetro inferior a $3 \mu \mathrm{m}$, como presentemente observado, devem ser consideradas libriformes, segundo as recomendações do IAWA Committee (1989). A norma COPANT (1973), utilizada na descrição das espécies mencionadas, vale-se apenas do tipo de pontoação (simples ou areolada) para a classificação das fibras em libriformes ou fibrotraqueídeos.

No material em estudo, o comprimento médio de fibras e elementos vasculares, bem como a freqüência de vasos, situam-se dentro da amplitude verificada para o conjunto de Mirtoídeas.

A ausência de cristais no parênquima axial de Myrcianthes gigantea permite diferenciar a espécie de Feijoa sellowiana, Eugenia involucrata (Marchiori, 1984b), Myrrhinium loranthoides, Blepharocalyx salicifolius e 
Plinia rivularis. A presença de máculas medulares, ao contrário, não tem valor diagnóstico, decorrendo de danos físicos causados por intempéries, insetos ou patógenos.

\section{CONCLUSÕES}

A análise anatômica da madeira de Myrcianthes gigantea (Legr.) Legr. permite a formulação das seguintes conclusões:

- A estrutura microscópica concorda, em linhas gerais, com o descrito para o conjunto das Mirtáceas;

- A ausência de traqueídeos vasicêntricos, tidos como predominantes na família, e de cristais no parênquima axial, são aspectos importantes para diferenciar a espécie de algumas Mirtoídeas nativas do Rio Grande do Sul;

- A presença de poros solitários, de parênquima axial apotraqueal, de raios heterogêneos e de fibras com pontoações areoladas, confere primitividade ao xilema secundário, estando de acordo com o referido na literatura para a família Myrtaceae.

\section{REFERÊNCIASBIBLIOGRÁFICAS}

Burger, L. M., Richter, H. G. Anatomia da Madeira. São Paulo: Ed. Nobel, 1991. 154p.

Copant-Comissão Panamericana de Normas Técnicas. Descrição macroscópica, microscópica e geral da madeira - esquema I de recomendação. Colômbia, 1973. 19p. (COPANT 30).

Denardi, L. Estudo anatômico do lenho e morfologia foliar de Blepharocalyx salicifolius (H.B.K.) Berg, em duas regiões do Rio Grande do Sul. 2004. 94f. Dissertação (Mestrado em Engenharia Florestal) - Universidade Federal de Santa Maria, Santa Maria, RS.

Denardi, L., Marchiori, J. N. C., Ferreira, M. R. Anatomia da madeira de Plinia rivularis (Camb.) Rotman. Balduinia, n. 3, p. 21-25, Santa Maria, 2005.

Dujardin, E. P. Eine neue Holz-Zellulosenfaerbung. Mikrokosmos, n. 53, p. 94, 1964.
IAWA Committee. IAWA list of microscopic features for hardwood identification. IAWA Bulletin, v.10, n. 3, p. 218-359, 1989.

Legrand, C. D., Klein, R. M. Mirtáceas. In: Reitz, P. R. Flora Ilustrada Catarinense. Itajaí: Herbário Barbosa Rodrigues, 1978. p.770.

Marchiori, J. N .C. Estudo anatômico do xilema secundário de algumas espécies dos gêneros Acacia e Mimosa, nativas no Estado do Rio Grande do Sul. 1980. 186f. Dissertação (Mestrado em Engenharia Florestal) - Universidade Federal do Paraná, Curitiba.

Marchiori, J. N. C. Anatomia descritiva do lenho de Feijoa sellowiana Berg. Ciência \& Natura, Santa Maria, v. 6, p. 117-125, 1984a.

Marchiori, J. N. C. Anatomia da Madeira de Eugenia involucrata DC. (Myrtaceae). Ciência \& Natura, Santa Maria, v. 6, p. $127-136,1984$ b.

Marchiori, J. N. C. Anatomia descritiva da madeira de murtilho, Myrrhinium loranthoides (Hook. et Arn.) Burret, Myrtaceae. Rev. Centro de Ciências Rurais, Santa Maria, v. 14, p. 43-50, 1984c.

Marchiori, J. N. C. Estudo microscópico da madeira de sete-capotes, Campomanesia guazumaefolia (Camb.) Berg, Myrtaceae. Ciência Rural, Santa Maria, v. 28, n. 1, p. 47-51, 1998.

Marchiori, J. N. C., Muñiz, G. I. B. Anatomia descritiva da madeira de Myrceugenia myrtoides Berg. Ciência \& Natura, Santa Maria, v. 9, p. 113-120, 1987b.

Marchiori, J. N. C., Muñiz, G. I. B. Estudo anatômico da madeira de Myrceugenia glaucescens (Camb.) Legr. et Kausel. Ciência \& Natura, Santa Maria, v. 10, p. 105-113, 1988.

Marchiori, J. N. C., Brum, E. T. Anatomia da madeira do guamirim-facho, Calyptranthes concinna DC. Ciência Rural, Santa Maria, v. 27, n. 2, p. 217-222, 1997.

Marchiori, J. N. C., Sobral, M. Dendrologia das angiospermas: Myrtales. Santa Maria: UFSM, 1997.304 p.

Metcalfe, C. R., Chalk, L. Anatomy of the Dicotyledons. Oxford: Clarendon Press, 1972. v. 2, p. 621.

Rotman, A. D. Las espécies argentinas del género Myrcianthes (Myrtaceae). Darwiniana, San Isidro, v. 22, n. 1-3, p. 109-123, 1979. 